\title{
Optical CDMA (O-CDMA) Technology Demonstrator (TD) for 2D Codes
}

\author{
A. J. Mendez, V. J. Hernandez, C. V. Bennett, \\ W. J. Lennon, and R. M. Gagliardi
}

This article was submitted to the

IEEE Laser and Electo Optical Society (LEOS) annual meeting 26-30 October 2003

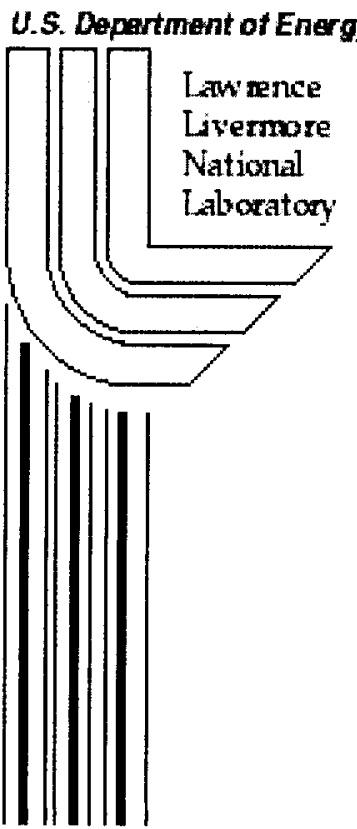

\section{October 26, 2003}


This document was prepared as an account of work sponsored by an agency of the United States Government. Neither the United States Government nor the University of California nor any of their employees, makes any warranty, express or implied, or assumes any legal liability or responsibility for the accuracy, completeness, or usefulness of any information, apparatus, product, or process disclosed, or represents that its use would not infringe privately owned rights. Reference herein to any specific commercial product, process, or service by trade name, trademark, manufacturer, or otherwise, does not necessarily constitute or imply its endorsement, recommendation, or favoring by the United States Government or the University of California. The views and opinions of authors expressed herein do not necessarily state or reflect those of the United States Government or the University of California, and shall not be used for advertising or product endorsement purposes. 


\title{
Optical CDMA (O-CDMA) Technology Demonstrator (TD) for 2D Codes
}

\author{
Antonio J. Mendez \\ Mendez R\&D Associates, P.O. Box 2756, El Segundo, CA 90245, Phone: (310) 640-0497, MendezRDA(a)AOL.com \\ Vincent J. Hernandez*a, Corey V. Bennett*, and William J. Lennon*, \\ *Lawrence Livermore National Laboratory (LLNL), P.O. Box 808, L-229, Livermore, CA 94551; \\ 'University of California at Davis, Department of ECE, Davis, CA 95616 \\ Robert M. Gagliardi \\ Department of EE-Systems, University of Southern California, Los Angeles, CA 90089-2565
}

\begin{abstract}
A TD based on wavelength/time codes, configured to multiplex and transmit 32 asynchronous Gigabit Ethernet data flows (GbE over O-CDMA), is described. The TD is user and data rate scalable.

\subsection{Introduction}

O-CDMA technology is interesting for local area and access networks because of its ability to aggregate (multiplex) and broadcast asynchronous, concurrent, bursty data flows without requiring optical/electrical/optical (O/E/O) conversion [1,2]. More recently, O-CDMA has also been considered as an enabler for an all-optical packet switch technique $[3,4]$. Among the types of O-CDMA codes, $2 \mathrm{D}$ codes are receiving increasingly more attention because of their superior spectral efficiency (S.E.) compared to direct sequence codes, especially if intensity modulation/direct detection (IM/DD) schemes are used [5,6,7]. The type of O-CDMA 2D codes used in the TD are based on folded optimum Golomb rulers [8]. This method of generating $2 \mathrm{D}$ optical orthogonal codes (OOCs) permits the designer much flexibility in tailoring them to be easily implemented and reconfigured while using only available (e.g., DWDM) technologies.
\end{abstract}

\subsection{O-CDMA Technology Demonstrator (TD)}

The TD is based on wavelength/time (W/T) matrix codes. The code construction produces more codes (32) than constituent wavelengths (8), so the coding is acting as a wavelength multiplier. To reduce costs and complexity, a "central office" generates an Encodable Carrier (EC) that is distributed to the users by means of a tree topology network. The EC is a time-frequency comb with 100 ps (the chip time) RZ pulses, a repetition frequency of $1.25 \mathrm{GHz}$, and eight wavelengths (C35-C42 on the ITU grid). Using the first four of the eight chips in the bit for the coding gives a $50 \%$ guard-time (GT) to avoid inter-symbol interference, ISI [8]. Users encode the EC with their code and impress NRZ GbE data on the encoded EC. Encoded data is broadcast to the other users by means of a $32 \times 32$ star coupler or linear bus. Encoders/ decoders are based on AWGs, $1 \times 4$ couplers, and delay-line arrays. The TD is currently configured for 32 GbE users but is scalable to 64-80 users (by redesigning the codes) and/or to higher data rates (by scaling the RZ pulse, its repetition rate, and the delay-lines). The TD architecture is shown in Figure 1.

\subsection{Set-up and Preliminary Results}

Figure 2 shows the TD installed in a 19" rack. The $481 \times 4$ couplers are in four $2 \mathrm{U}$ enclosures; the $32 \times 32$ star coupler is in a $1 \mathrm{U}$ enclosure; and the $18 \mathrm{AWG}$ are in an $8 \mathrm{U}$ enclosure. The TD architecture defines the wiring diagram among these enclosures and active components such as the multi-wavelength source. The computed and measured output of decoder M9 with 0 to 3 interferers are shown, respectively, in Figure 3 and Figure 4. The decoded signal is clearly visible over the multi-access interference, MAI (which is seen building up with the number of interferers). Analyses, Excel spreadsheet simulations, and R-Soft LinkSim simulations all indicate that the visibility of the signal over the MAI as shown in Fig. 4 will be good until 16 concurrent users (using $50 \%$ GT), giving an S.E of $0.25 \mathrm{bit} / \mathrm{s} / \mathrm{Hz}$ [8]. For $>16$ users, MAI suppression (e.g., optical hard-limiting, OHL) is required. Earlier results show that OHL is sufficient to support at least 24 concurrent users, an S.E. of $0.37 \mathrm{bit} / \mathrm{s} / \mathrm{Hz}$ [8]. The O-CDMA TD is intended to explore and extend the boundaries of O-CDMA in terms of asynchronous users and associated data rates. 


\section{Acknowledgments}

This effort was supported in part by U.S. Department of Energy SBIR Phase II Grant ER83277 and performed under the auspices of the U.S. Department of Energy by the University of California LLNL under contract No. W-7405-Eng-48 and a subcontract to ER83277. The collaboration between MRDA and LLNL was carried out under Cooperative Research and Development Agreement TC-2051-02.

\section{References}

[1] P. R. Prucnal, M. A. Santoro, and T. R. Fan, "Spread spectrum fiber-optic local area network using optical processing", J. Lightwave Tech., vol. LT-4, pp. 547-554 (1986).

[2] T. Pfeiffer, B. Deppisch, M. Witte, and R. Heidemann, "Optical CDMA Transmission for Robust Realization of Complex and Flexible Multiple Access Networks", Conf. Proc. OFC'99, WM51, p. 344. [3] N. Wada, H. Harai, and F. Kubota, " $40 \mathrm{~Gb} / \mathrm{s}$ Interface, Optical Code Based Photonic Packet Switch Prototype”, Conf. Proc. OFC'03, FS7, p. 801.

[4] D. Gurkan, S. Kumar, A. Sahin, A. Willner, K. Parameswaran, M. Fejer, D. Starodubov, J. Bannister, P. Kamath, and J. Touch, "All-Optical Wavelength and Time 2-D Code Converter for DynamicallyReconfigurable O-CDMA Networks using a PPLN Waveguide”, Conf. Proc. OFC'03, FD6, p. 654.

[5] E. Park, A. J. Mendez, and E. Garmire,"Temporal/spatial optical CDMA networks-design, demonstration, and comparison with temporal networks", IEEE Photon. Tech. Lett., Vol. 4, p.1160-1162 (1992).

[6] H. Fathallah. L. A. Rusch, and S. LaRochelle, "Passive Optical Fast Frequency-hop CDMA Communications System", IEEE/OSA J. Lightwave Tech. vol. 17, pp. 397-405 (1999).

[7] R. M. H. Kim, L. R. Chen, and J. Bajcsy, "Design and Performance of 2D Codes for WavelengthTime Optical CDMA", IEEE Photon. Tech. Lett., vol. 14, pp. 714-716 (2002).

[8] A. J. Mendez, R. M. Gagliardi, V. J. Hernandez, C. V. Bennett, and W. J. Lennon, "Design and Performance Analysis of Wavelength/Time (W/T) Matrix Codes for Optical CDMA", accepted for publication, IEEE/OSA J. Lightwave Technol., Special Issue on Optical Networks, Vol. 21, TBD, Dec., 2003.

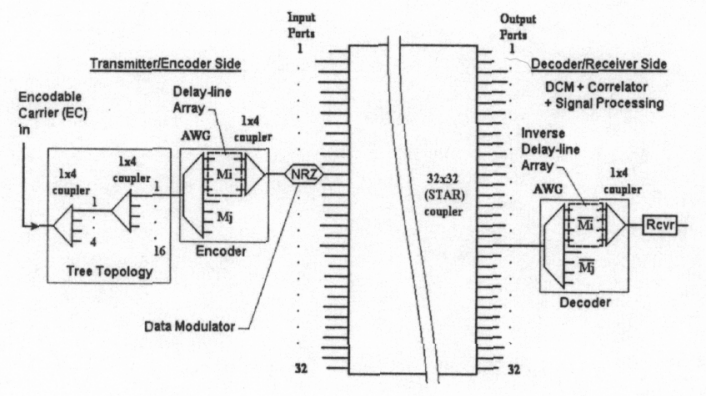

Figure 1. TD Top Level Architecture.

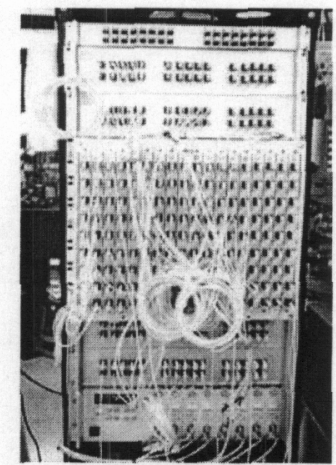

Figure 2. TD Set-up.

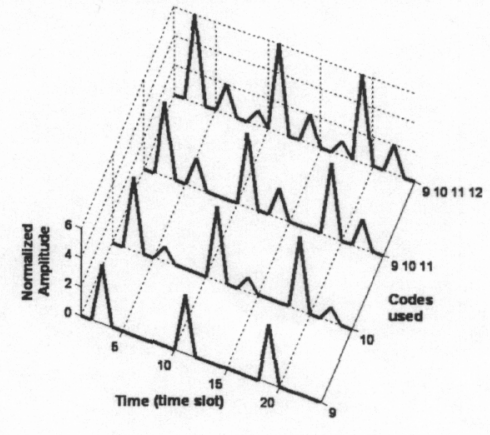

Figure 3. Computed Signal+MAI (0-3 Interferers).

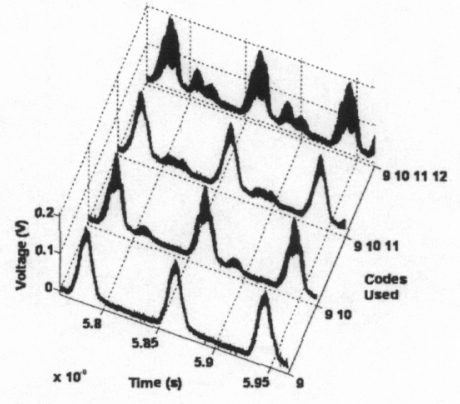

Figure 4. Measured Signal+MAI (0-3 Interferers). 